\title{
NONLINEAR DYNAMICS IN PARTICLE ACCELERATORS
}




\title{
WORLD SCIENTIFIC SERIES ON NONLINEAR SCIENCE
}

\author{
Editor: Leon O. Chua \\ University of California, Berkeley
}

\section{Series A. MONOGRAPHS AND TREATISES}

\section{Published Titles}

Volume 9: Frequency-Domain Methods for Nonlinear Analysis: Theory and Applications G. A. Leonov, D. V. Ponomarenko, and V. B. Smimova

Volume 12: Attractors of Quasiperiodically Forced Systems T. Kapitaniak and J. Wojewoda

Volume 13: Chaos in Nonlinear Oscillations: Controlling and Synchronization M. Lakshmanan and K. Murali

Volume 14: Impulsive Differential Equations A. M. Samoilenko and N. A. Perestyuk

Volume 15: One-Dimensional Cellular Automata B. Voorhees

Volume 16: Turbulence, Strange Attractors and Chaos

$$
\text { D. Ruelle }
$$

Volume 17: The Analysis of Complex Nonlinear Mechanical Systems: A Computer Algebra Assisted Approach
M. Lesser

Volume 20: Chaotic Dynamics
C. Mira, L. Gardini, A. Barugola and J.-C. Cathala

Volume 21: Hopf Bifurcation Analysis: A Frequency Domain Approach
G. Chen and J. L. Moiola

Volume 23: Nonlinear Dynamics in Particle Accelerators R. Dilāo and R. Alves-Pires

\section{Forthcoming Titles}

Volume 18: Wave Propagation in Hydrodynamic Flows
A. L. Fabrikant and Y. A. Stepanyants

Volume 19: Continuum Mechanics via Problems and Exercises Edited by M. E. Eglit and D. H. Hodges

Volume 22: Chaos and Complexity in Nonlinear Electronic Circuits M. J. Ogorzalek

Volume 24: From Chaos to Order G. Chen and X. Dong 
Series Editor: Leon O. Chua

\title{
NONLINEER DYNAMICS IN \\ PARTICLE ACCELEEATORS
}

\author{
Rui Dilão \\ Rui Alves-Pires \\ Instituto Superlor Técnico, \\ Portugal
}




\section{Published by}

World Scientific Publishing Co. Pte. Ltd.

P O Box 128, Farrer Road, Singapore 912805

USA office: Suite 1B, 1060 Main Street, River Edge, NJ 07661

UK office: 57 Shelton Street, Covent Garden, London WC2H 9HE

\section{British Library Cataloguing-in-Publication Data}

A catalogue record for this book is available from the British Library.

\section{NONLINEAR DYNAMICS IN PARTICLE ACCELERATORS}

Copyright $\odot 1996$ by World Scientific Publishing Co. Pte. Ltd.

All rights reserved. This book, or parts thereof, may not be reproduced in any form or by any means, electronic or mechanical, including photocopying, recording or any information storage and retrieval system now known or to be invented, without written permission from the Publisher.

For photocopying of material in this volume, please pay a copying fee through the Copyright Clearance Center, Inc., 222 Rosewood Drive, Danvers, MA 01923, USA. In this case permission to photocopy is not required from the publisher.

ISBN $981-02-2517-2$

Printed in Singapore by Uto-Print 


\section{Preface}

Particle accelerators are instruments of increasing importance in scientific research and industry, playing a prominent role in our understanding of the constituents of matter and their interactions. On the other hand, the great dimensions and resources involved in their construction and use have a significant public impact.

The scientific research and the high degree of technological development achieved in the construction of particle accelerators and associated equipment are stimulating the invention of new products and materials, the introduction of new methods of manufacturing, defining the frontiers of technology.

This book is an introductory course to accelerator physics at the level of graduate students. It was written for a large audience which includes users of accelerator facilities, accelerator physicists and engineers, and undergraduates aiming to learn the basic principles of construction, operation and application of accelerators. It covers the basic material for a one semester course in the physics and design of synchrotrons. In particular, chapter 1 is for the non-specialized reader.

In order to feel the main problems associated with the design of synchrotrons, we have included a software package to help the design of real synchrotrons, keeping control of the optical properties of beams. This software tool is based on the Mathematica [Wol91] programming language, and enables the reader to test its own skills in the design of synchrotrons. To guide the user in the optics of particle beams, we have included several examples of synchrotron design.

On the other hand, the new concepts of dynamical systems developed in the last twenty years give the theoretical setting to analyze the stability of particle beams in accelerators. In this book a common language to both accelerator physics and dynamical systems is integrated and developed, aiming to eliminate the diffculties faced by accelerator physicists, engineers and applied mathematicians when they try to join efforts in the attempt to improve the performance of synchrotron accelerators.

In chapter 1, after an historical introduction to the development of accelerators, the physical principles for their design and construction are described. This chapter is self-contained and meets the needs of a simple course for the user of particle 
accelerator facilities. It was written at a very basic level.

In chapter 2 , the equations of motion of a test particle in a synchrotron accelerator are derived. Transverse and longitudinal motion are treated separately. The physics of radio-frequency cavities is derived and the nonlinear Poincaré map for the longitudinal motion is analyzed. Several case studies of stable orbits in synchrotrons and the principle of alternating gradient focusing are analyzed.

In chapter 3, some basic concepts of the Theory of Dynamical Systems are introduced and some of the results of the theory of nonautonomous differential equations and Poincaré maps are reviewed. Mathematical details are omitted and referred to specialized articles. The concepts of tune and dynamic aperture, familiar to the accelerator physicist, are explored in the context of dynamical systems where they have the meaning of rotation number and stability limit around a fixed point. The geometric aspects of chaotic behavior in conservative maps and homoclinic and heteroclinic explosions are explained. The concepts of linear, nonlinear and parametric resonance are discussed in detail, as they play an important role in the working point of a synchrotron. These results will be important in chapters 5 and 6 where the parameters of dynamically nonlinear synchrotrons are analyzed and predicted.

In chapter 4, the Courant and Snyder linear theory of the transverse motion of particles in synchrotron accelerators is presented and its stability analyzed. These methods are the main tools for accelerator design. The thin-lens approximation is introduced and the general Poincaré map for the transverse motion is derived.

Basic techniques of the theory of dynamical systems are presented in chapter 4 and are used to analyze beam aberrations and to calculate the chromatic correction. We obtain the general formula for the chromaticity parameter, which is critical in the choice and location of sextupoles in large synchrotrons. The problems of momentum correction, field errors and imperfections are analyzed in detail.

With the tools developed in chapter 4 , a simple computer program was developed by the authors to design synchrotrons. The code uses the energy, characteristics of magnets and straight sections as input parameters. This program determines the stability of the design orbit, calculates chromaticities, Poincaré maps, tunes, slip factor and the popular Courant and Snyder beta, alpha and gamma functions, and dispersion.

In chapter 5, the Poincaré map for a synchrotron with nonlinear magnetic fields is 
derived. Based on the theory of dynamical systems exposed in chapter 3 , nonlinear optimization strategies for the strength of sextupoles and tune shift are derived. The problem of nonlinear tune resonances and dynamic aperture is analyzed and discussed in detail. This material corresponds to previous published work of the authors. In order to compare theoretical results with real design situations we have compared our predictions with the design simulations of the Large Hadron Collider under design and study at CERN. The predictions obtained agree within a relative error of the order of $1 \%$.

Chapter 6 concerns the study of the beam-beam interaction. Stability conditions, tune and tune shift values for the nonlinear beam-beam map are derived. The dimensions of the chaotic annular region around the central design orbit are estimated.

We would like to thank the Fermilab for the permission to reproduce the photos in the text and to World Scientific for the use of some figures in chapters 5 and 6 , previously published by the authors in the International Journal of Bifurcations and Chaos. We are indebted to our colleagues of CERN and Fermilab with whom we have had long discussions on the subjects of this book.

Finally, we want to thank Ana Noronha for the critical reading of the entire manuscript. One of the authors (R. D.) also wants to acknowledge her continuous encouragement during the preparation of this book. 
This page is intentionally left blank 


\section{Conventions and Notations}

$\beta(s)$ Courant and Snyder beta function.

$\alpha(s)$ Courant and Snyder alpha function.

$\gamma$ Relativistic factor, $\gamma=1 / \sqrt{1-v^{2} / c^{2}}$, where $c$ is the speed of light in vacuum.

$\mu(s)$ Phase advance in the interval $\left[0,2 \pi \nu_{0}\right]$.

$\nu_{0}$ Tune or rotation number of the synchronous particle in the plane transverse to the design orbit. $\nu_{0 x}$ and $\nu_{0 z}$ are the horizontal and vertical tunes.

$\nu_{b b}$ Beam-beam linear tune.

$\Delta \nu$ Tune shift.

$\phi(s)$ Phase advance in the interval $[0,2 \pi]$.

$\rho$ Cyclotron radius.

$\varepsilon$ Beam emittance.

$\xi$ Chromaticity.

$\eta$ Slip factor.

$\omega_{R F}$ Cyclotron frequency.

$B_{0}$ Strength of dipolar magnetic field in tesla $(\mathrm{T})$. We take always $B_{0}>0$, implying that positive charged particles circulate anticlockwise and negative charged particles clockwise. (Notice that in older literature $B$ is called magnetic induction).

$h$ Harmonic number.

$k_{f}, k_{d}$ Normalized quadrupolar strengths.

$\tilde{k}_{f}, \tilde{k}_{d}$ Normalized quadrupolar strengths times the length of quadrupoles.

$K^{(2)}$ Normalized sextupolar strengths.

$L_{s}$ Length of the synchrotron measured along the design or reference orbit.

$p_{s}$ Reference momentum of the synchronous particle.

$R$ Mean radius of a synchrotron, $R=L_{s} / 2 \pi$.

$s$ Longitudinal coordinate along the design orbit. 
This page is intentionally left blank 


\section{Contents}

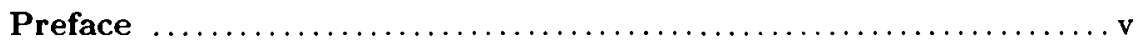

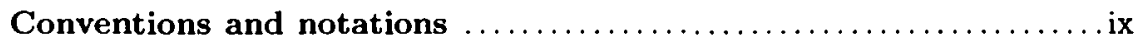

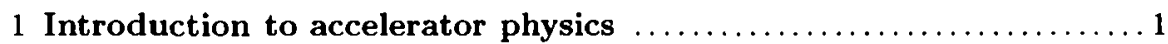

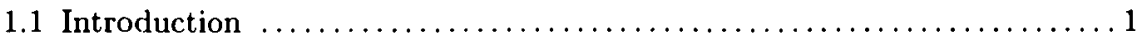

1.2 Accelerators in medicine and industry $\ldots \ldots \ldots \ldots \ldots \ldots \ldots \ldots \ldots \ldots$

1.3 Nonlinear phenomena in particle accelerators $\ldots \ldots \ldots \ldots \ldots \ldots \ldots \ldots 6$

1.4 Acceleration and guiding of charged particles.

Physical principles..................................... 7

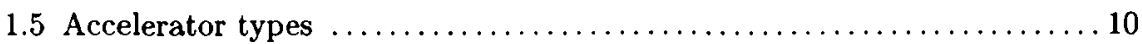

1.5.1 Linear accelerators $\ldots \ldots \ldots \ldots \ldots \ldots \ldots \ldots \ldots \ldots \ldots \ldots \ldots \ldots \ldots, 10$

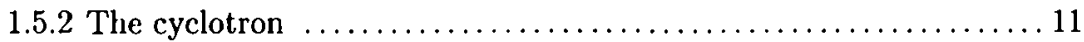

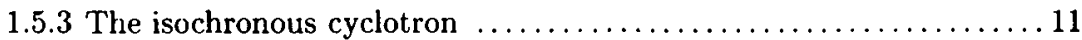

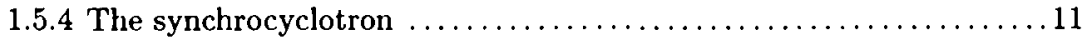

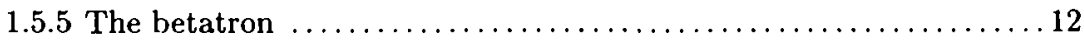

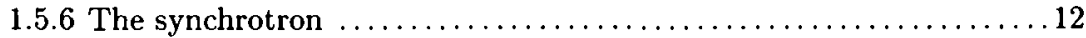

1.6 How to build a synchrotron accelerator ....................... 13

1.6.1 Confinement ...................................... 13

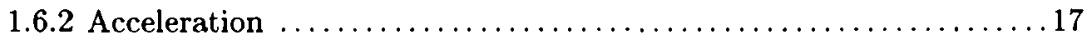

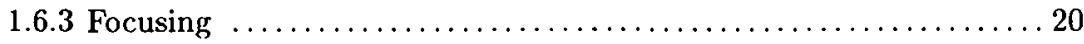

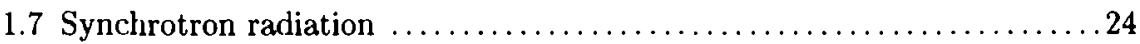

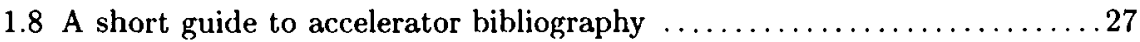

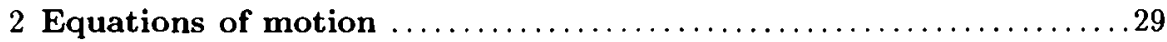

2.1 Equations of motion in the transverse plane. $\ldots \ldots \ldots \ldots \ldots \ldots \ldots \ldots$

2.1.1 Transverse motion in straight sections $\ldots \ldots \ldots \ldots \ldots \ldots \ldots \ldots . \ldots \ldots$

2.1.2 Transverse motion in straight sections with special purpose magnets 34

2.1.3 Transverse motion inside dipoles $\ldots \ldots \ldots \ldots \ldots \ldots \ldots \ldots \ldots \ldots . \ldots \ldots$

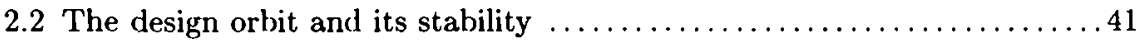


2.3 Focusing properties of pairs of quadrupoles $\ldots \ldots \ldots \ldots \ldots \ldots \ldots \ldots . \ldots 4$

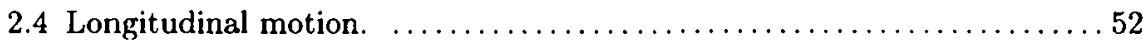

3 Introduction to the qualitative theory

of nonlinear differential equations $\ldots \ldots \ldots \ldots \ldots \ldots \ldots \ldots \ldots \ldots$

3.1 Phase space, fixed points and stability. .....................65

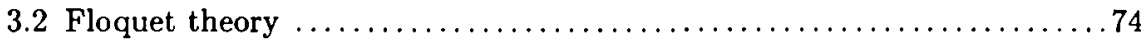

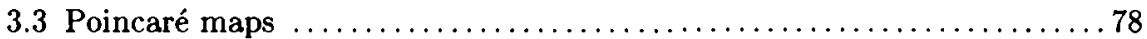

3.4 Maps of the plane. Homoclinic and heteroclinic orbits $\ldots \ldots \ldots \ldots \ldots 81$

3.5 Normal forms for two-dimensional conservative maps ............. 90

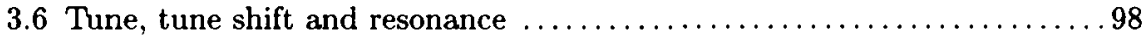

\section{Dynamics and stability of guiding and focusing.}

Linear optics of synchrotrons

4.1 Transfer matrices, Poincaré maps and integrability of the equations of motion .................................. 104

4.2 The Courant and Snyder Beta function ..................... 107

4.3 Invariants, emittance, beam envelope and admittance $\ldots \ldots \ldots \ldots \ldots 115$

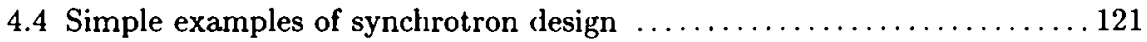

4.5 Off-momentum motion. The dispersion function $\ldots \ldots \ldots \ldots \ldots \ldots \ldots 126$

4.6 Focusing-defocusing (FD) and focusing-bending-defocusing (FBD)

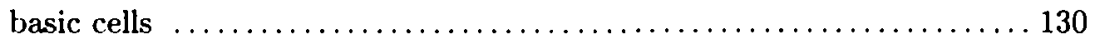

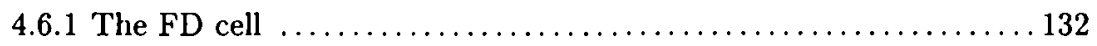

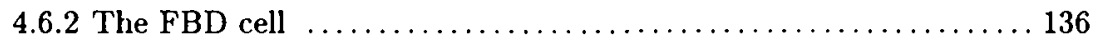

4.7 Chromaticity and chromatic correction $\ldots \ldots \ldots \ldots \ldots \ldots \ldots \ldots \ldots \ldots$

4.8 Linear field errors . ......................................... 145

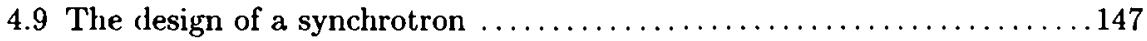

5 Nonlinear motion in the transverse plane: sextupoles $\ldots \ldots \ldots \ldots 153$

5.1 Nonlinear equations of motion in the thin lens approximation ........ 155

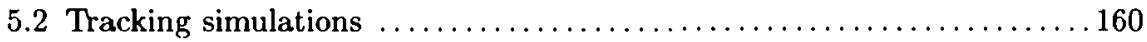

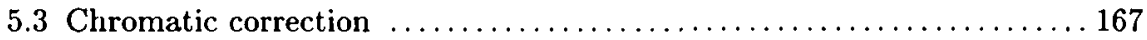

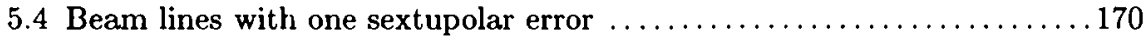

5.5 Coupled motion in the two transverse directions $\ldots \ldots \ldots \ldots \ldots \ldots \ldots 172$

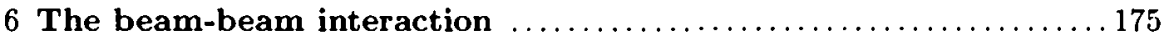

6.1 Equations of motion for the beam-beam effect $\ldots \ldots \ldots \ldots \ldots \ldots \ldots \ldots 177$ 
6.2 The general Poincaré map for localized interactions . . . . . . . . . . 178

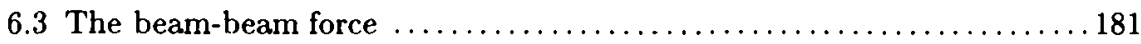

6.4 Dynamics of the linearized beam-beam Poincaré map . . . . . . . . 182

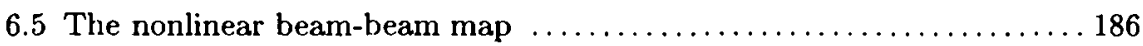

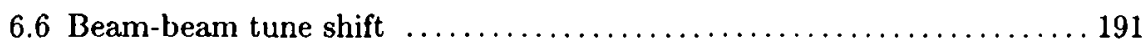

\section{Appendices}

A1 Motion of relativistic charged particles in uniform

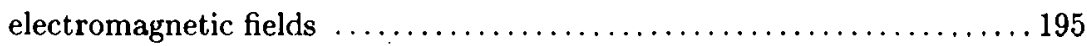

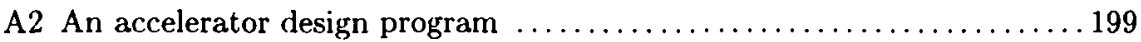

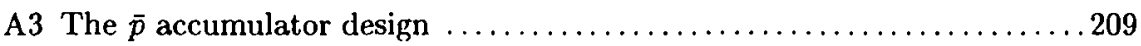

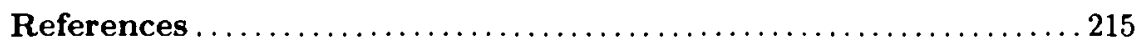

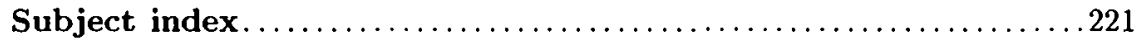

